\title{
Round 4B: How Real Is Clinical Wisdom? A Further Reply to Held
}

\author{
RONALD B. MILLER ${ }^{\mathrm{a}, \mathrm{b}}$ \\ ${ }^{\text {a }}$ Department of Psychology, St. Michael's College, Colchester, VT \\ ${ }^{\mathrm{b}}$ Correspondence concerning this article should be addressed to Ronald B. Miller, Director, Graduate Program in \\ Clinical Psychology, Box 288, One Winooski Park, Colchester, VT 05439. \\ Email: rmiller@smcvt.edu
}

\begin{abstract}
Held (2006a; 2006b) has critiqued my position (Miller, 2004; Miller, 2006a) that the centrality of suffering to clinical practice in psychology makes moral concerns also inherent in, and central to, clinical judgment and practice. Held does not deny the importance of basic human suffering or moral concerns to the clinical situation. Instead, she denies the claim that the objective elements of a clinical situation are inextricably entwined with moral issues. Held defends the position that there is an objective component to clinical practice that can be separated from moral concerns by distinguishing between moral and ethical values, and separating the means from the ends of psychotherapy. Her defense of the existence of causal mechanisms in clinical problems and interventions is dependent on the position that reasons are causes, and her view that the clinical generalizations from a case study database are causal claims. In response, I distinguish between the bare-bones factual account of a person's behavior that is objective but clinically impoverished, and a full scale clinical judgment imbued with moral import. The game of chess is examined as an example of a reason-governed interpersonal practice in which reasons for acting can be distinguished from causes of behavior.
\end{abstract}

Key words: clinical wisdom; epistemology of practice; moral philosophy

I shall confine myself again to those portions of the Held (2006b) paper in question that directly comment on my views on the nature of clinical knowledge and clinical research. I believe that I am correct in asserting that Barbara Held and I share a deep commitment to developing a discipline of clinical psychology that requires us to be guided by reason, emotional integrity, evidence, and a moral commitment to attempt to alleviate human suffering. These are complex and reflexive problems. Reason, morality, and emotion (and to a lesser extent, evidence) are also matters of concern in the clinical situation itself. To be considering the role that these factors play in the epistemology of clinical psychology is doubly vexing. In talking about how reason, evidence, emotion, and moral concern intersect in the creation of knowledge we are not referring only the development of the client's problem, but also to the therapist's understanding of the client's problem, and the articulation and conceptualization of that understanding into clinical theory. It is this complexity that places upon us yet another 
Round 4b: How Real Is Clinical Wisdom? A Further Reply To Held

R.B. Miller

Pragmatic Case Studies in Psychotherapy, http://pcsp.libraries.rutgers.edu

Volume 2, Module 4, Article 7, pp. 1-8, 10-16-06 [copyright by author]

requirement, namely, a capacity for intellectual humility, a tolerance for incomplete answers and even only half-articulated questions. I continue to find my understanding of the problem illuminated by this exchange of views, for which I am indebted to both Barbara Held and Dan Fishman.

As I review Held's first and second exchanges in this series, it appears to me that amidst these shared concerns for reason, emotional integrity, evidence and moral commitment, Held's approach views the application of reason and evidence to clinical problems as logically distinct from the application of moral reasoning to these same clinical problems. (After a few brief introductory observations, I shall for the purposes of this discussion omit consideration of the logic of emotional concerns in clinical knowledge. While it is relevant, and no doubt also controversial, it has not centrally featured in the discussions in this series and I fear would only add confusion rather than clarity were it introduced here.) Unlike many clinical scientists in our midst, Held does not minimize the practical importance of emotional or moral issues in the subject matter of clinical psychology. Emotion and moral principles are just as real for Held as reason and evidence. Nevertheless, in her logic of clinical knowledge, reason and evidence operate independently of the moral aspects of knowledge generation in clinical psychology. What follows is an attempt to examine the intersection of factual circumstances and moral judgment in the creation of clinical evidence, clinical judgment and clinical theories of intervention.

\section{WHERE IS THE OBJECTIVITY IN CLINICAL WISDOM?}

For me, reason and moral concern enter into the clinical situation in tandem, as dual logical requirements of knowledge. I want to know and understand what is going on in order to answer two questions: (1) Is there a problem here? (2) Can I be of assistance? In order to answer these two questions, I need to understand the factual circumstances (the who, what, where and how of investigative reporting (Levine, 1980) and behavioral description) and the moral concerns presented by a particular case (again leaving aside for now the emotional dynamics). Working out how reason operates at the intersection of relatively objective "facts" and moral concern is what makes the epistemology of clinical practice so difficult and complex.

My assertion that clinical assessment (or diagnosis) and treatment are inherently moral undertakings means that if I remove the implicit moral judgments from a diagnosis like major depression, or from a treatment like cognitive therapy of depression, I am no longer in the clinical realm. I am not saying that there is no reality in the consulting room other than the clinical reality that my moral judgments partially frame or constitute. However, the reality that remains once the clinical judgment is removed is impoverished and anemic. It is from the point of view of clinical psychology essentially incoherent and fails to create a moral obligation, under the circumstances, for the second person in the room to do something to help alleviate the suffering in the room. I don't see how Held's use of Tjeltveit's (1998) distinction between ethical obligations and moral aspirations alters the manner in which moral or ethical concerns interact with a set of circumstances to constitute a clinical observation or judgment. 
I return again to the ambiguities of a situation that might result in a diagnosis of major depression. What is left in the room in the absence of the moral imperative that converts brute facts into clinical phenomena is something like this: one person is telling another person how they are for example, crying frequently, not sleeping or eating the way they typically do, not very focused upon performance tasks, angry at their current circumstance, etc. The person so reporting may also be demonstrating these same behaviors in the room at the time. Also left in the room are the behaviors of the second person who may or may not be listening attentively, talking or asking questions, or speaking on the telephone to someone else, etc. There is a reality to this situation that does not depend entirely on the moral viewpoint of the participants or a third party observer, but it is not very robust, for even in everyday life we bring our moral judgments into such situations, deciding whether to feel compassion for the individual in question, and whether to offer help. However, if we strip our description of the reality in the room even of this everyday moral concern, the objective reality remaining, while not insignificant, falls far short of having any clinical significance whatsoever.

Those features of the clinical situation that are not dependent on the observer's moral point of view (Baier, 1958) are similar to Taylor's (1973) concept of "brute facts" which he thought were too meager to form the basis of even a developmental or social psychology, to say nothing of the complexity of observed phenomena in clinical psychology. The clinical reality is formed by the synthesis of these morally neutral behavioral circumstances or features of the situation with complex judgments of intentions, reasons for acting, goals, meanings, and moral values. This synthesis requires both the morally neutral, for lack of a better word, factual givens, and the moral judgments and principles in order to logically constitute clinical reality.

Held performs an extremely valuable service to psychotherapy theorists and researchers by holding our philosophical feet to the epistemological fire by demanding that we recognize that our clinical theories are accountable to a non-(psychological) theory dependent reality and we do not have carte blanche in making claims about who benefits from a particular approach to therapy, and in what contexts. Returning to the example above of the person with ostensible signs of major depression, were this to be a person who had lost a dear loved one in the past year, and who was living in a sub-culture where grieving family members are expected to be so effected for at least one year following the loss, we would see this as a normal grieving process in which it would be counter- therapeutic to intervene. The clinician's moral values about how one ought to behave in the face of loss operate in conjunction with the theory neutral occurrences to "create" a clinical problem with concomitant treatment expectations, or not. But these values do not create the reports of crying, change in sleep and eating patterns, social withdrawal, etc. In the absence of these kinds of factual descriptions the question of depression is moot. In such a context, it makes no sense to even ask the question, "Is this person depressed?"

On the other hand, one must also remember that in the absence of some moral viewpoint on how one ought to live one's life, the most exhaustive, neutral (what our behavioral colleagues call) behavioral description of the circumstances in an ostensibly depressed individual's life, it is equally impossible to ask, "Is this person doing all right or is she 
R.B. Miller

Pragmatic Case Studies in Psychotherapy, http://pcsp.libraries.rutgers.edu

Volume 2, Module 4, Article 7, pp. 1-8, 10-16-06 [copyright by author]

depressed?" For depression means all of that behavior plus something like the claim "and a person shouldn't (or shouldn't have to) feel that way." There is always an implicit "ought" or "should" in every diagnosis, and in every treatment goal or plan. This being the case clinical judgments and clinical treatments are implicitly moral statements, and if one attempts to separate the fact from the value as Held argues we should, I believe we thereby render the clinical reality unintelligible. The very meaning of these clinical terms is, in part, moral.

Held advocates for the view of Meehl (2004, personal communication) and others that the goals of therapy are often moral, but whether the therapy actually reaches those goals can be ascertained by independent observers irrespective of the moral values held by those observers. Thus is denied any problem of the incommensurability of competing therapeutic modalities. Held relies on the naturalistic fallacy argument here, asserting that my view conflates the "ought" and the "is." I think it is clear from my argument above why this appears to be the case. A clinical judgment is an implicit moral judgment conjoined to a set of neutrally definable circumstances. There is both fact and value in the statement, "John has a depressive disorder." The naturalistic fallacy admonishes us never to deduce an "ought" from an "is"- that is, never deduce a moral statement about how one "ought" to act from a straightforward statement of facts about how one "is" acting. Clinical statements that include diagnostic evaluations or assessments are not simple factual reports. Such reports already include an implicit "ought" and so moral conclusions can logically follow from making such assertions.

\section{DO CLINICIANS CAUSE CLIENTS TO CHANGE?}

Clinical language is a moral language, and that sets certain limits on what we can expect of clinical research and clinical knowledge. In Facing Human Suffering: Psychology and psychotherapy as Moral Engagement (Miller, 2004) I argue for the increased use of comprehensive case studies as a means of capturing the morally nuanced aspects of clinical reality. In chapter six I specifically call for greater attention to the quality of evidence used in supporting claims made in case studies about clinical effectiveness and clinical process. By urging the inclusion of detailed accounts of life history, life circumstances, and clinical process and dialogue in everyday language free of highly abstract, psychological theory- dependent constructs, I hoped to see the comprehensive clinical case study contribute in important ways to the knowledge base of clinical psychology. Authors of case studies are urged to also examine the explicit and implicit moral values that informed the therapist's clinical work, as well as those moral values that inform the author's perspective on the case. As Held notes I agree with Dan Fishman that an archive of such cases would be a great benefit to the development of clinical knowledge in the field, and that patterns of effective clinical practice would be likely to emerge that would be grounded in clinical reality rather than the artificial de-moralized knowledge that so often results from traditional empirically inspired group design experiments.

Held questions how one can assert, as I do, that generalizable clinical knowledge will emerge from a case study archive or database ( at least for therapists sharing a common value base) while also rejecting as I do that the knowledge so generated is causal in nature. My answer 
Round 4b: How Real Is Clinical Wisdom? A Further Reply To Held

R.B. Miller

Pragmatic Case Studies in Psychotherapy, http://pcsp.libraries.rutgers.edu

Volume 2, Module 4, Article 7, pp. 1-8, 10-16-06 [copyright by author]

to this is again to return to the moral nature of clinical knowledge. For me, the moral sphere, or the ethical sphere as Held refers to it, is never solely about the operation of causal forces. The view of morality that I have long espoused is grounded in the post-WWII analytic moral philosophy of among others Toulmin (1950), Baier (1958), Hare (1963), Rachels (1993) who argued that morality is as much about giving reasons for acting as it is about emotion or social conditioning. To have a moral position is to be able to give good reasons for actions. It is part of being a creature who has the capacity to reason and to be governed by reason. Held argues that some analytic philosophers such as Erwin (1997) have maintained that "reasons are causes" and so a psychology that identifies the reasons we do things is nevertheless still a causal psychology. This makes some sense so far as it goes, for we do sometimes think of reason as compelling us to act in certain ways, much the way a causal force in nature (a strong gust of wind) may compel us to move ( though as I indicated in my previous response to Held I think such a linguistic idiom that conflates reasons and causes is only partially supported by ordinary language and is extremely problematic in the moral and legal sphere), but the next step in the argument is even more problematic.

How does one investigate the "reasons that are causes" in a clinical science? Does one do research to isolate casual factors as one does in biology or chemistry with control groups, dependent and dependent variables, statistical tests of significance, etc.? In her first response Held (2006a) seemed to agree with many of the criticisms leveled at the use of hypothesis testing experimental research in clinical psychology. She seemed to think that the search for empirical generalizations was a necessary first step to building a knowledge base for the field that has been neglected thus far in the development of our discipline. It is unclear why Held is so determined to establish that reasons are causes, and that psychology can make causal claims, since the research she seeks to expand is not capable of evaluating causal claims. Perhaps, she sees this as a preliminary step to developing a discipline based upon causal principles.

Still, I think it a mistake to collapse reasons into causes. Reasons act like causes not because they operate on us like blind forces of nature, but because we live in social environments that are governed by norms, laws and rules. These predictable regularities of our social environment dictate certain goals that we should aspire to, and various means for accomplishing those ends. As reason governed creatures we evaluate these goals and means and choose strategies for acting in the world.

Defenders of this view often use the game of chess as illustrative of reason and rulegoverned behavior. The moves of a skilled chess player are reasoned. When a move is made it is made for a number of reasons including but not limited to the following: (a) a desire to win; (b) knowledge of the rules; (c) knowledge of strategies of attack and defense; and(d) estimates of the opponents ability and strategies. These reasons for acting do require certain moves, or "make" a person choose a given move. They may be said even to cause certain moves. Yet this is a far cry from the way in which the muscle spasms and movements around the neck and mouth of a person with tardive dyskinesia are caused by brain damage resulting from the side effects of psychotropic medications. Intelligent behavior, reason governed behavior, of which I take moral 
Round 4b: How Real Is Clinical Wisdom? A Further Reply To Held

R.B. Miller

Pragmatic Case Studies in Psychotherapy, http://pcsp.libraries.rutgers.edu

Volume 2, Module 4, Article 7, pp. 1-8, 10-16-06 [copyright by author]

behavior to be one variant, is caused by reasons in a manner quite distinct from how behavior may be caused by purely physiological factors.

As Henry Murray (1938) observed many years ago, if one wants to know the reasons for a person's actions one starts by inquiring of the person in question why they would do such a thing. While this may not be the end of the story it must be the beginning. Often, the answer is sufficient, and the hunt for the "cause" of the problem is complete as illustrated in the following vignette. When a 15 year old adolescent who has just made a near lethal suicide attempt tells us that he did this because he wanted to rejoin his recently deceased mother who died unexpectedly from a coronary, we have been given the reason for his suicide attempt. Of course, there is more to know in order to fill out the story. He has always lived in a high conflict family situation where his mother was his only friend or support. She was the only support as well for his interest in art, and without her he is unable to do the one thing he loved other than her (drawing), and has nothing to look forward to other than further abuse at the hands of his father and older siblings. Occasionally at school he is able to draw in an art class, but the teacher is highly competitive with him, undermines his work and sends him to the principle for insubordination when he objects to such treatment. For these reasons he chose to try to take his own life in a violent fashion rather than live with such a bleak future.

To return to the chess example, we may discover that most beginning chess players who have learned the etiquette of the game nevertheless often fail to appreciate the strategic value of the knight, and over estimate the value of the rook. This results in early exit from the board of the knights. What is the cause of this? It is not a failure in cognitive processes, or frontal lobe damage, but rather a failure in understanding how chess games unfold, and the ingredients of a successful end-game strategy. The beginner fails to understand how the rules of the game, when followed over 15-25 sets of moves, create certain outcomes.

This is revealed more fully by trying to understand the reasons for acting of a second person sitting at a chessboard with a partner, but who is not interested in actually playing by the rules of chess. If two people sit down at a chessboard with no intention of playing chess and proceed to throw the pieces at one another, then the explanation of their actions will not include the etiquette of chess or the strategic rules of the game. However, there will be other social rules and rule-governed actions that pertain and which will ultimately provide a framework for the reason they are throwing chess pieces at one another.

When we understand the explicit and implicit rules that a person is trying to follow, their expectations about the rules that others are following, the areas where the rules are confusing or opaque, and their goals and expectations about outcomes achieved in following various rules, we have gone a long way to understanding the reasons people act the way they do. Some of these rules are moral while others are purely procedural. In either case, rule governed actions provide a structure, regularity, predictability, and generalizability to human actions. Our case studies may reveal these patterns in the clinical realm and thus contribute to understanding the reasons for human suffering and successful strategies ("moves") for therapeutic intervention. Using the 
causal language of science in this context seems to me to do more to conceal than reveal the sources of such suffering. Usually explanations framed in scientific language convey a message that the depersonalized forces within or around an individual ( abstract variables like "neuroticism," "ego strength," "expressed emotions") conspire outside of personal control to produce human suffering. In response to these de-moralized problems treatments are offered that are equally de-personalized and that attempt to cause people to change (often in spite of themselves). This notion that one person can cause another to radically alter their way of living in the world seems to me fundamentally flawed and over-simplified. We do not make a difference in one another's lives by being causally efficacious but rather by being morally engaged.

\section{CONCLUSION}

In summary, Held and I agree that suffering is an important construct to reclaim from conceptual garbage bin of the history of psychopathology. We also agree on the importance of (psychological) theory- neutral behavioral evidence in validating clinical claims. Held seems to believe that one can have evidence about human suffering that is independent of one's moral stance or judgments, whereas I believe that human suffering is inherently a moral construct, and consequently that clinical knowledge claims about clinical reality are inherently, but not exclusively, moral judgments. Clinical judgments begin with the recognition of a pre-clinical reality of circumstances to which we attach the meaning "and it shouldn't be so."

The moral realm is in part in the realm of reason. We look for reasons to act or not act, for justifications for our actions, and the actions of others. As reason is also concerned with the realm of factual circumstances, reason is a bridge between facts and values. Reasons are embedded in social rules and regulations, and in personal goals and intentions. Human reason creates the structure, regularity, and generalizability of human actions in a way quite distinct from the regularity produced by the causal forces of nature. The search for solutions to clinical problems is more akin to the search to the answers to moral problems and dilemmas than to the search for the causal forces of nature.

It is for this reason that I advocate for restoring the importance of comprehensive case studies as a vehicle for the development of clinical knowledge, and for a reduction in the emphasis on positivist inspired Randomized Clinical Trials in psychotherapy research. It seems to me that the case study does justice to the nature of clinical evidence as a synthesis of factual information with moral judgment. It allows us to explore the reasons for psychological problems, and the impact of the understanding of these reasons on the life of the client.

\section{REFERENCES}

Baier, K (1958). The moral point of view. Ithaca: Cornell University Press. Erwin, E. (1997). Philosophy and psychotherapy: Razing the troubles of the brain. London: Sage. 
Hare, R.M. (1965). Freedom and Reason. London: Oxford University Press.

Held, B. (2006a). Round 1: Does case study knowledge need a new epistemology? Pragmatic Case Studies in Psychotherapy [Online], Vol. 2(4), Article 2. Available: http://hdl.rutgers.edu/1782.1/pcsp_journal .

Held, B.S. (2006b) Round 3: Regarding objectivity and causality: A Rejoinder to Fishman and Miller. Pragmatic Case Studies in Psychology \{Online\}, Vol. 2(4), Article 5. Available: http://hdl.rutgers.edu/1782.1/pcsp_journal

Levine, M. (1980). Investigative reporting as a research method: An analysis of Bernstein and Woodward's All the President's Men.

American Psychologist, 35, 626-638.

Meehl, P. (personal communication).

Miller, R.B. (2004). Facing human suffering: Psychology and psychotherapy as moral engagement. Washington, DC: APA Books.

Miller, R. B. (2006). Round 2B: Facing human suffering-A response to Held. Pragmatic Case Studies in Psychotherapy [Online], Vol. 2(4), Article 4. Available: http://hdl.rutgers.edu/1782.1/pcsp_journal

Murray, H. (1938). Explorations in personality. New York: Oxford University Press.

Rachels. J. (1993). The elements of moral philosophy (2 ${ }^{\text {nd }}$ ed.). New York: McGraw- Hill.

Taylor, C. (1973). Peaceful coexistence in psychology: Social Research, 40, 55-82.

Toulmin, S. (1950). Reason in ethics. Cambridge: Cambridge University Press.

Tjeltveit, A. C. (1999). Ethics and values in psychotherapy. London: Routledge. 